TI 2011-110/3

Tinbergen Institute Discussion Paper

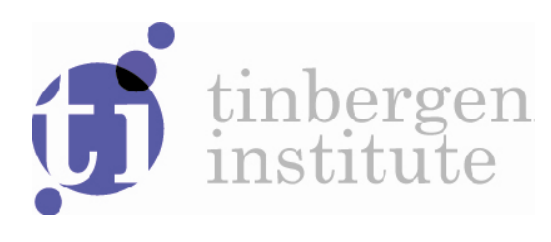

Regional Efficiency Improvement by Means of Data Envelopment Analysis

through Euclidean Distance

Minimization including Fixed Input

Factors - An Application to Tourist

Regions in Italy

Soushi Suzukil

Peter Nijkamp²

Piet Rietveld ${ }^{2}$

I Sapporo University, Sapporo, Japan;

2 VU University Amsterdam, and Tinbergen Institute. 
Tinbergen Institute is the graduate school and research institute in economics of Erasmus University Rotterdam, the University of Amsterdam and VU University Amsterdam.

More TI discussion papers can be downloaded at http://www.tinbergen.nl

Tinbergen Institute has two locations:

Tinbergen Institute Amsterdam

Gustav Mahlerplein 117

1082 MS Amsterdam

The Netherlands

Tel.: +31(0)205251600

Tinbergen Institute Rotterdam

Burg. Oudlaan 50

3062 PA Rotterdam

The Netherlands

Tel.: +31(0)10 4088900

Fax: $+31(0) 104089031$

Duisenberg school of finance is a collaboration of the Dutch financial sector and universities, with the ambition to support innovative research and offer top quality academic education in core areas of finance.

DSF research papers can be downloaded at: http://www.dsf.nl/

Duisenberg school of finance

Gustav Mahlerplein 117

1082 MS Amsterdam

The Netherlands

Tel.: +31(0)20 5258579 


\title{
Regional efficiency improvement by means of data envelopment analysis through Euclidean distance minimization including fixed input factors - an application to tourist regions in Italy
}

\author{
Soushi Suzuki ${ }^{1}$, Peter Nijkamp ${ }^{2}$ and Piet Rietveld ${ }^{2 *}$ \\ 1 Sapporo University, Department of Economics, Nishioka3-7-3-1, Toyohira-ku, 062-8520 Sapporo, Japan \\ ${ }^{2}$ VU University Amsterdam, Department of Spatial Economics, De Boelelaan 1105, 1081 HV Amsterdam, the Netherlands
}

\begin{abstract}
Standard Data Envelopment Analysis (DEA) is characterized by uniform proportional input reduction or output augmentation in calculating improvement projections. This paper develops a new Euclidean Distance Minimization model in the context of DEA in order to derive a more appropriate efficiency-improving projection model by means of a weighted projection function. The model is extended to the situation where some factor inputs are fixed, for instance, due to lumpiness or natural constraints. The extended DEA model is illustrated in the context of regional planning by using a data set on Italian tourist destination regions.
\end{abstract}

JEL classification: C444, D610, L830, R150

Keywords: Euclidean Distance Minimization (EDM), Data Envelopment Analysis (DEA), Multiple Objective Quadratic Programming (MOQP), efficiency improving projection, tourist efficiency

*Corresponding author (e-mail: prietveld@feweb.vu.nl)

\section{Tourism as a multi-dimensional economic challenge}

This study aims to present a new methodology for analyzing and presenting efficiency-improving opportunities for tourist regions. It is as such not directly concerned with regional tourism policy, but rather with the information needed to make a meaningful, operational and comparative assessment of the total performance of tourist areas and of ways to improve such performance. Thus, the emphasis is on theory and modelling, although empirical findings on tourist regions in Italy will be offered as an illustration.

Tourism has become a major economic sector with potentially high revenues for attractive tourist destinations (Wall and Mathieson 2006). The modern tourist sector is nowadays operating on a competitive international market with a high degree of product variety that may meet the demands of a diversity of customers. Clearly, tourism is a multi-faceted and multi-purpose activity (e.g. beach tourism, cultural tourism, sports tourism, nature tourism, etc.) that has to operate within often strict limits of socially or ecologically sustainable development - or carrying capacity - of the local environment (see Ryan and Aicken 2005; Apostolopoulos and Gayle 2001; Coccossis and Mexa 2004; Fusco Girard and Nijkamp; Nelson et al. 1993; Heath and Wall 1992). Awareness is currently growing that environmental degradation caused by tourism may erode the basis of tourism, so that tourism has to seek for long-range sustainable strategies in a globally competitive sector (see 
Matias et al. 2007; Giaoutzi and Nijkamp 2006; Shaw and Williams 2002; Tisdell 2001). In the past decades Europe has become a major player in global tourism; it is at present attracting more than 50 percent of international tourist arrivals and may continue to be a major magnet for tourists in the future, depending on the development of income, leisure time, transportation means and local sustainability of tourist resources.

It is noteworthy that competition between tourist destinations is rapidly rising, not only between Europe and the rest of the world, but also between individual countries in Europe, while we have also witnessed fierce competition between regional tourist destinations inside the same country. An important question is, therefore: Which regions have - in retrospect - been successful in attracting a major part of tourist flows and under which performance conditions? The present paper draws on previous research by Cracolici et al. (2008), in which DEA and stochastic production frontier methods were deployed to investigate the efficiency of 103 Italian tourist regions. In the latter study, also a literature survey was offered on the use of DEA approaches in tourist research, which will not be repeated in the present paper.

Cracolici (2005) has argued that from an economic perspective each tourist destination has a region-specific tourist production function which may be characterized by a combination of different inputs (e.g. types of accommodation or tourist facilities) which altogether generate a set of tourist outputs (e.g. visitors, tourist revenues). If we assume that the tourist sector is a multi-product market with a variety of outputs, we may characterize the tourist production function as a vector-valued production function: $\underline{y}=f(\underline{\boldsymbol{X}})$, where $\underline{y}$ is a multidimensional set of tourist outputs, while $\underline{\boldsymbol{X}}$ is a vector of inputs. Similar formulations can be found in Morey and Dittman (1995) and Barros (2005). The successful combination of different inputs leads to a varied set of more or less efficient outputs. The question then is: Which actor (i.e. region) has been most efficient in generating various outputs by a smart combination of inputs, under given locational conditions, and is there sufficient scope for this actor to improve its performance? This question is essentially a vector optimization problem which may be specified as a multiple objective programming (MOP) problem (see Section 2), a method closely linked to DEA.

Section 3 provides a brief description of DEA. A basic element of DEA is that the performance of each inefficient actor may be compared to an efficient alternative which may serve as a benchmark to determine which steps (in terms of excessive inputs to be removed, or outputs to be augmented) have to be made in order to make it efficient under ideal conditions. Section 4 will then be devoted to the development of a new method to serve this purpose, based on calculating the Euclidean distance between actual outcomes of a production process and what is referred to as the 'production possibility (or efficiency) frontier'. This is called the Euclidean Distance Minimization (EDM) approach, through which we are able to generate appropriate efficiency improvement projections that may be instrumental for regional tourist strategies. A realistic extension towards the situation of regionally fixed input factors is given in Section 5 . This new modelling approach will then be applied empirically in Section 6 to a data set on Italian visitors' flows to tourist destinations in Italy with the aim to identify the most efficiently operating tourist regions in Italy, as well as to derive an optimal quantitative efficiency improvement target for all input and output values on the basis of our EDM model. The paper will be concluded in Section 7 with a research agenda on promising pathways concerning regional tourist competition analysis.

\section{Tourist production as a MOP problem}

From a formal economic efficiency perspective, the tourist production function can be interpreted as a MOP problem where different variables act as key forces for the generation of different objective functions (output criteria) to be maximized. Such a multi-objective efficiency problem may formally be described as the following vector optimization problem (see, e.g., Nijkamp et al. 1990):

$$
\max \underline{w}=\underline{f}(\underline{z}), \underline{z} \in Z,
$$


where $\underline{W}$ is a vector of different objective functions, $\underline{Z}$ a vector of instruments (or decision parameters) to be manipulated so as to achieve an overall maximum of the decision problem concerned, and $\mathrm{Z}$ a real-valued feasible decision space. Function $\underline{f}$ is a vector-valued transformation function that links multiple instruments to multiple objectives.

If the above MOP problem is formulated as a linear decision problem (MOLP), it can be written as follows:

$$
\max \underline{w}=V \underline{z}, \underline{Z} \in Z \Rightarrow\{\underline{z} \mid R \underline{z} \leq \underline{s}, \underline{z} \geq \underline{0}\}
$$

where $\underline{W}, \underline{Z}$ and $\underline{S}$ are real-valued vectors, and $V$ and $R$ are real-valued matrices (see, e.g., Goicoechea et al. 1992; Sawaragi et al. 1985; Steuer 1986).

An important concept in a MOP model is the notion of an efficient (or non-dominated) solution, defined as follows for the MOP model (2): $\underline{Z}^{*} \in Z$ is an efficient solution if (and only if) there is no other $\underline{Z} \in Z$ for which $V \underline{Z} \geq V \underline{z}^{*}$ and $V \underline{Z} \neq V \underline{Z}^{*}$. The set of all efficient solutions is usually called the 'efficiency set'.

The idea of MOP is to seek efficient solutions within a feasible decision space and to indicate projections for the improvement of inefficient points. The optimal direction of the projection depends on the weights (or trade-off parameters) attached by decision-making units (DMUs) to the respective objective functions. In the practice of decision theory, these MOP models are deployed as ex ante decision-making instruments by DMUs. Such models are particularly useful in the case of mutually conflicting objectives that cannot be reduced to a single one. For example, in the case of tourism planning, the objective functions might be: tourist revenues, bed-nights (for both domestic and international tourism), protection of cultural heritage, environmental sustainability, etc. (see also Giaoutzi and Nijkamp 1993). The decision variables (input factors) may also be manifold, such as: capital investments in tourism, cultural resources, quality of service, etc. In general, a typical tourism MOP problem in region $\mathrm{r}(\mathrm{r}=1, \ldots, \mathrm{R})$ may be represented as follows (see also Cracolici, 2005):

tourist output $_{\mathrm{r}}=f_{r}\{$ historico-cultural capital , human capital , natural capital, labour $\}$,

where tourist output in region $\mathrm{r}$ may be regarded as a multidimensional vector representation of distinct output objectives. This ex ante MOP representation prompts the question whether an integration or combination with DEA (normally focused on ex post multidimensional efficiency analysis) is possible. This will be treated in the next section.

\section{Efficiency improvement projection in DEA}

DEA aims to investigate the relative efficiency of a DMU on the basis of various inputs and outputs. In one of the seminal publications on DEA, Charnes et al. (1978) developed a quantitative measure for assessing the relative efficiency of DMUs by using a frontier method that aims to determine the maximum possible volume of outputs, given a set of inputs. In this framework, it is possible to assess ex post the (in)efficiency of a DMU on the basis of the distance to the production frontier. DEA, which can be regarded as a form of non-parametric linear programming, has over the past decades become an operational tool for analysing efficiency problems in various industrial sectors, where (in)efficiency is interpreted as the relative distance from an actual situation to the production frontier function.

In the Charnes et al. (1978) model (abbreviated hereafter as the CCR model), the efficiency of each DMU is measured 
by comparing it with all the other DMUs, assuming constant returns to scale. Let us denote $\mathrm{DMU}_{o}$ as the $\mathrm{DMU}$ to be evaluated, where 0 ranges from $1,2, \ldots$ to $\mathrm{J}$. The standard CCR formulation is in the form of a fractional programming problem $\left(F P_{o}\right)$ to obtain optimal values for the weights $v$ and $u$ associated with the inputs and outputs:

$$
\begin{array}{r}
\left(F P_{o}\right) \quad \max _{v, u} \quad \theta=\frac{\sum_{s} u_{s} y_{s o}}{\sum_{m} v_{m} x_{m o}} \\
\text { s.t. } \quad \frac{\sum_{s} u_{s} y_{s j}}{\sum_{m} v_{m} x_{m j}} \leq 1,(j=1, \cdots, J) \\
v_{m} \geq 0, u_{s} \geq 0,
\end{array}
$$

where $\theta$ represents an objective variable (efficiency score) for each actor $0, \quad x_{m j}$ is the volume of input $m(m=1, \ldots, M)$ for $\mathrm{DMU}_{j}(j=1, \ldots, J)$, and $y_{s j}$ the output $s(s=1, \ldots, S)$ of $\mathrm{DMU}_{j}$, while $v_{m}$ and $u_{s}$ are the weights given to input $m$ and output $s$, respectively.

The CCR model (4) can be shown to have the following equivalent linear programming $\left(L P_{o}\right)$ specification for any individual $\mathrm{DMU}_{0}$ :

$$
\begin{array}{ll} 
& \left(L P_{o}\right) \quad \max _{v, u} \quad \theta=\sum_{s} u_{s} y_{s o} \\
\text { s.t. } \quad & \sum_{m} v_{m} x_{m o}=1 \\
- & \sum_{m} v_{m} x_{m j}+\sum_{s} u_{s} y_{s j} \leq 0 \quad(\mathrm{j}=1, \ldots, \mathrm{J}) \\
& v_{m} \geq 0, u_{s} \geq 0 .
\end{array}
$$

The advantage of (5) is not only that it allows the use of standard LP algorithms, but also that it leads to a dual formulation of (5), $D L P_{o}$, that proves to be useful for the analysis of slacks in terms of inputs and outputs. We can formulate the dual problem as follows, where vector notation proves to be useful:

$$
\begin{array}{ll} 
& \left(D L P_{o}\right) \quad \min _{\theta, \lambda} \theta \\
\text { s.t. } & \theta x_{o}-X \lambda \geq 0 \\
& Y \lambda \geq y_{o} \\
& \lambda \geq 0
\end{array}
$$

where the transposed (T) expression $\lambda=\left(\begin{array}{lll}\lambda_{1}, & \cdots & \lambda_{J}\end{array}\right)^{T}$ is a non-negative vector corresponding to the presence of slacks for each DMU; $\quad X$ is an $(M \times J)$ input matrix and $Y$ is an $(S \times J)$ input matrix.

We may now define the input excesses $S^{-} \in R^{m}$ and the output shortfalls $S^{+} \in R^{s}$ and identify them as 'slack' vectors in the following standard from of a DEA model: 


$$
\begin{aligned}
& s^{-}=\theta x_{o}-X \lambda \\
& s^{+}=Y \lambda-y_{o} .
\end{aligned}
$$

On the basis of these results we can now formulate the following two steps to compute for each $\mathrm{DMU}_{0}$ the corresponding efficiency score $\theta$ and the slack variables $\left(\lambda, s^{-}, s^{+}\right)$:

(1): We solve $\mathrm{DLP}_{0}$. Let the optimal objective value be $\theta^{*}$; based on the optimal weights $\left(v^{*}, u^{*}\right)$, we get:

$$
\theta^{*}=\frac{\sum_{s} u_{s}^{*} y_{s o}}{\sum_{m} v_{m}^{*} x_{m o}} .
$$

(2): Given the value of $\theta^{*}$, we solve the following $\operatorname{LP}$ model using $\left(\lambda, s^{-}, s^{+}\right)$as slack variables:

$$
\begin{array}{ll} 
& \max _{\lambda, s-, s+} \omega=e s^{-}+e s^{+} \\
\text {s.t. } & s^{-}=\theta^{*} x_{o}-X \lambda \\
& s^{+}=Y \lambda-y_{o} \\
& \lambda \geq 0, \quad s^{-} \geq 0, \quad s^{+} \geq 0,
\end{array}
$$

where $\omega$ is a scalar objective variable, and $e$ is a unit vector.

The optimal values for $\left(\lambda, s^{-}, s^{+}\right)$resulting from Step 2 will be denoted as $\left(\lambda, s^{-}, s^{+}\right) *$. These slack values can be used to determine "improvement projections" for each alternative input variable or output variable with an efficiency score below 1 . The improvement projection $\left(\hat{x}_{o}, \hat{y}_{o}\right)$ is a point on the efficient frontier that is linked to the input-output profile of a certain DMU in the following way:

$$
\begin{aligned}
& \hat{x}_{o}=\theta^{*} x_{o}-s^{-*} \\
& \hat{y}_{o}=y_{o}+s^{+*} .
\end{aligned}
$$

These relations indicate that the efficiency of $\left(x_{0}, y_{0}\right)$ for $\mathrm{DMU}_{0}$ can be improved if the input values are reduced radially by the ratio $\theta^{*}$; then the input excesses $s^{-*}$ are removed. Similarly, the efficiency can be improved if the output values are enlarged by the output shortfall $s^{+*}$.

This standard formulation implies a uniform input reduction in the improvement projections as shown in Figure 1 (see $\theta^{*}=\mathrm{OC}$ 'OC). The same holds for an output augmentation (see Figure 2). This is indeed a simple approach, but is it also the most appropriate method? Is a uniform approach not too restrictive for a DMU who may need flexible adjustment directions for his objectives or instruments? Clearly, in principle, there is an infinite number of improvement projections on the efficient frontier line. The improvement projection of the original DEA models is only one practical solution, based on a uniform input 
reduction or a uniform output augmentation. To avoid the uniformity restriction, we will develop in our study an alternative improvement projection based on a new approach which is related to the actual data characteristics of each specific DMU. In Section 4, we therefore propose this new method that is geared towards an appropriate treatment of the existence of an infinite number of improvement projections on the efficient frontier line.

\section{FIGURES 1 AND 2 ABOUT HERE}

\section{The Euclidean Distance Minimization (EDM) approach}

Where the standard DEA models have focused on a uniform input reduction or a uniform output augmentation function in the improvement projections, we present here a Euclidean Distance Minimization (EDM) model approach that offers a new contribution to efficiency enhancement by deploying a weighted projection function. At the same time, it serve to address both input reduction and output augmentation. Our EDM searches for the point on the efficient frontier that is as close as possible to the DMU's input and output vector. And, the EDM model developed in the present study retains the advantage of the standard DEA approach that the measurement units of the different inputs and outputs need not be identical. An additional property of the EDM method is that the improvement projection does not need to incorporate a priori information. Our approach bears some resemblance to the directional distance function model developed by Chambers et al. (1996) in the context of production function analysis.

The improvement solution in the original CCR-input model imposes the condition that the input values are reduced radially by a uniform ratio $\theta^{*}\left(\theta^{*}=\mathrm{OD}^{\prime} / \mathrm{OD}\right.$ in Figure 2$)$. That is to say, the improvement solution for any arbitrary inefficient $\mathrm{DMU}_{\mathrm{D}}$ is $\mathrm{D}^{\prime}$ in Figure 2 (in cases where the input space is a non-weighted $x$-space). The general specification of a CCR model is frequently based on a normal $x$ or $y$-space (non-weighted space) (see Figure 1), in contrast to Figures 2 and 3 , which are based on weighted $x$ or $y$-spaces. Weighted spaces can be investigated regarding the impact of distance functions on improvement projections for input and output variables in the following way (see Cooper et al. 2006).

We take as a point of departure the efficiency score $\theta^{*}$ defined in (9), based on the optimal weights $\left(v^{*}, u^{*}\right)$ obtained for each $\mathrm{DMU}_{0} . \quad\left(v^{*}, u^{*}\right)$ is the set of most favourable weights for $\mathrm{DMU}_{0}$ in the sense of maximizing the respective ratio scales. $v_{m}{ }^{*}$ is the optimal weight for input $m$, and its size indicates how much in relative terms the item contributes to the set of inputs. Similarly, $u_{s}^{*}$ does the same for the output $s$. Furthermore, if we examine each item $v_{m}{ }^{*} x_{m o}$ in the total input: $\sum_{m} v_{m}^{*} x_{m o}$, we can derive the relative importance of each item with reference to the value of each $v_{m}{ }^{*} x_{m o}$. The same holds for $u_{s}{ }^{*} y_{s o}$, where $u_{s}^{*}$ provides a measure of the relative contribution of $y_{s o}$ to the sum of outputs.

\section{FIGURE 3 ABOUT HERE}

In this study we use the optimal weights $u_{s}{ }^{*}$ and $v_{m}{ }^{*}$ from (5), and then develop our alternative improvement projection model, EDM. A visual presentation of this new approach is given in Figures 2 and 3. In this approach a generalized non-general distance function is deployed to assist a DMU in improving its efficiency by a movement towards the efficiency frontier surface. For this purpose we use the minimization of Euclidean distance in weighted spaces. A suitable form of multidimensional projection function serving to improve efficiency is given by a Multiple Objective Quadratic Programming (MOQP) model which aims to minimize the aggregated input reductions as well as the aggregated output augmentations.

The EDM approach developed in our study consists now of five steps which will are now briefly presented. We start with the well-known CCR approach outlined in Section 3. 
(1): Solve DLP in (6). Let the optimal objective value be $\theta^{*}$, and the obtained optimal weights $u_{s}{ }^{*}$ and $v_{m}{ }^{*}$.

(2): Using $\theta^{*}$, solve (9)-(12), so that we obtain $s^{-*}, s^{+*}$. Each DMU can then be categorized by $\theta^{*}, s^{-*}$ and $s^{+*}$, as follows:

(1) When $\theta^{*}=1, s^{-*}=s^{+*}=0$ : this is a situation of an efficient DMU.

(2) When $\theta^{*}=1, s^{-*} \neq 0$ or $s^{+*} \neq 0$ : improvement solutions are generated by means of formulas (13) and (14).

(3) When $\theta^{*} \neq 1, s^{-*} \neq 0$ or $s^{+*} \neq 0$ : improvement solutions are generated by the next steps 3,4 and 5 .

(3): Introduce the Euclidean distance functions $E$ and $E$ by means of (15) and (16), as shown in Figures 2 and 3 . And solve the following MOQP using $d_{m o}^{x}$ (the reduction distance for $x_{i o}$ ) and $d_{s o}^{y}$ (the augmentation distance for $y_{s o}$ ) as variables:

$$
\begin{gathered}
\min E=\sqrt{\sum_{m}\left(v_{m}^{*} x_{m o}-v_{m}^{*} d_{m o}^{x}\right)^{2}} \\
\min E=\sqrt{\sum_{s}\left(u_{s}^{*} y_{s o}-u_{s}^{*} d_{s o}^{y}\right)^{2}} \\
\text { s.t. } \sum_{m} v_{m}^{*}\left(x_{m o}-d_{m o}^{x}\right)=\frac{2 \theta^{*}}{1+\theta^{*}} \\
\sum_{s} u_{s}^{*}\left(y_{s o}+d_{s o}^{y}\right)=\frac{2 \theta^{*}}{1+\theta^{*}} \\
x_{m o}-d_{m o}^{x} \geq 0 \\
d_{m o}^{x} \geq 0 \\
d_{s o}^{y} \geq 0
\end{gathered}
$$

where $x_{m o}$ is the magnitude of input item $m$ for an arbitrary inefficient $\mathrm{DMU}_{0}$; and $y_{s o}$ is the magnitude of output item $s$ for an arbitrary inefficient $\mathrm{DMU}_{\mathrm{o}}$. The constraint functions (17) and (18) refer to the target values of input reduction and output augmentation.

An important question in the bi-modal approach (with both input reduction and output rise possibilities) is of course which of the two possibilities are most appropriate. In other words: is an optimal balance between these two options to be achieved? This problem of the balance between these contributions from the input and output side to achieve efficiency is dealt with as follows. The total efficiency gap to be covered by inputs and outputs is $\left(1-\theta^{*}\right)$. The input and the output side contribute according to their initial levels 1 and $\theta^{*}$, implying shares $\theta^{*} /\left(1+\theta^{*}\right)$ and $1 /\left(1+\theta^{*}\right)$ in the improvement contribution. Hence the contributions from both sides equal $\left(1-\theta^{*}\right)\left[\theta^{*} /\left(1+\theta^{*}\right)\right]$, and $\left(1-\theta^{*}\right)\left[1 /\left(1+\theta^{*}\right)\right]$.

Therefore, we find for the input reduction targets and the output augmentation targets the following expressions: 


$$
\begin{aligned}
& \text { Input reduction target: } \sum_{m} v_{m}^{*}\left(x_{m o}-d_{m o}^{x}\right)=1-\left(1-\theta^{*}\right) \times \frac{1}{\left(1+\theta^{*}\right)}=\frac{2 \theta^{*}}{1+\theta^{*}} \\
& \text { Output augmentation target: } \sum_{s} u_{s}^{*}\left(y_{s o}+d_{s o}^{y}\right)=\theta^{*}+\left(1-\theta^{*}\right) \times \frac{\theta^{*}}{\left(1+\theta^{*}\right)}=\frac{2 \theta^{*}}{1+\theta^{*}} .
\end{aligned}
$$

An illustration is given in Figure 4.

\section{FIGURE 4. ABOUT HERE}

The constraint function (19) refers to a limitation of input reduction, while constraint functions (20) and (21) express simultaneously the pressure of input reduction and output augmentation. It is now possible to calculate simultaneously the optimal distances $d_{m o}^{x^{*}}$ and $d_{s o}^{y^{*}}$ by using the above mentioned MOQP model (15)-(21), which can be solved by separately solving (15), (17), (19) and (20) for $d_{m o}^{x^{*}}$ and (16), (18) and (21) for $d_{s o}^{y^{*}}$.

(4): The distance minimization solution for an inefficient $\mathrm{DMU}_{\mathrm{o}}$ can then be expressed by means of formulas (24) and (25):

$$
\begin{aligned}
& x_{m o}^{*}=x_{m o}-d_{m o}^{x^{*}} ; \\
& y_{s o}^{*}=y_{s o}+d_{s o}^{y^{*}} .
\end{aligned}
$$

(5): In order to ascertain the presence and use of slacks for the input and output variables, we solve formula (3.3) and (3.6)-(3.9); by using $x_{m o}^{*}, y_{\text {so }}^{*}$, we obtain $\theta^{* *}, s^{-* *}, s^{+* *}$. In this case, we are sure that $\theta^{* *}$ is calculated as 1 . An optimal solution for any inefficient $\mathrm{DMU}_{\mathrm{o}}$ can be now expressed by means of equations (26) and (27):

$$
\begin{aligned}
& x_{m o}^{* *}=x_{m o}^{*}-s^{-* *} ; \\
& y_{s o}^{* *}=y_{s o}^{*}+s^{+* *} .
\end{aligned}
$$

By means of this EDM model, it is now possible to present a new efficiency improvement solution based on the standard CCR projection, with a balance between inputs and outputs. It means an increase in the options for meaningful efficiency improvement solutions in DEA. The main advantage of the EDM model is that it yields an outcome on the efficient frontier that is as close as possible to the DMU's actual input and output profile (see Figure 5).

\section{FIGURE 5. ABOUT HERE}

An additional advantage is that the EDM model retains the property of the standard DEA approach that the measurement units of the different inputs and outputs need not be identical, while the improvement projection in a EDM model does not need to incorporate a priori information. 


\section{Fixed factors in DEA}

\subsection{Exogenous input and output research in DEA}

We will now analyse the case where inputs and/or outputs are not (entirely) a matter of free choice for a DMU, at least not in the planning or decision period that is considered as relevant. To cope with this problem, Banker and Morey (1986) proposed a model where some inputs or outputs are exogenously given. This model formulation is also known as a 'fixed factor model', or a model with 'non-discretionary inputs'. It can be formulated in the following way:

$$
\begin{array}{r}
\min ! \quad \theta-\varepsilon\left(\sum_{m \in D} s_{m}^{-}+\sum_{s=1}^{S} s_{s}^{+}\right) \\
\text {s.t. } \quad \theta x_{m o}=\sum_{m=1}^{M} x_{m j} \lambda_{j}+s_{m}^{-}, m \in D \\
x_{m o}=\sum_{m=1}^{M} x_{m j} \lambda_{j}+s_{m}^{-}, m \in N D \\
y_{s o}=\sum_{s=1}^{S} y_{s j} \lambda_{j}-s_{s}^{+}, \quad s=1, \cdots, S,
\end{array}
$$

where all variables are constrained to be non-negative (except $\theta$ ); the symbol $m \in D$ refers to the set of 'discretionary' inputs; the symbol $m \in N D$ refers to the set of 'fixed' or 'non-discretionary' inputs; and $\varepsilon$ has a non-Archimedean infinitesimal value, implying that the above problem formulation is solved in two steps: first, $\varepsilon$ is set equal to zero on the basis of which the optimal value for $\theta$ is determined; in the second step, the optimal values for the slack variables are determined, given the optimal value of $\theta$.

It should be noted from the constraints that the variable $\theta$ is not included in (30) because the pertaining inputs are exogenously fixed. It is therefore not possible to vary them at the discretion or free choice of management. This is recognized by entering all $x_{m o}, m \in N D$ at their fixed value. Finally, we note that the pertaining slacks $s_{m}^{-}, m \in N D$ are omitted from the objective function. Based on the fixed factor formulation in the above model, we will now develop in Subsection 5.2 an adjusted fixed factor model in our EDM approach.

\subsection{Development of a EDM model with fixed factors}

In this subsection we present a version of the EDM model that takes into account the presence of factor rigidity. The efficiency improvement projection incorporating a fixed factor (FF) in an EDM model is presented in (32)-(38):

$$
\begin{aligned}
& \min E=\sqrt{\sum_{m \in D}\left(v_{m}^{*} x_{m o}-v_{m}^{*} d_{m o}^{x}\right)^{2}} \\
& \min E=\sqrt{\sum_{s \in D}\left(u_{s}^{*} y_{s o}-u_{s}^{*} d_{s o}^{y}\right)^{2}}
\end{aligned}
$$




$$
\begin{gathered}
\text { s.t. } \sum_{m \in D} v_{m}^{*}\left(x_{m o}-d_{m o}^{x}\right)+\sum_{m \in N D} v_{m}^{*} x_{m o}=1-\frac{\left(1-\theta^{*}\right)\left(1-\sum_{m \in N D} v_{m}^{*} x_{m o}\right)}{\left(1-\sum_{m \in N D} v_{m}^{*} x_{m o}\right)+\left(\theta^{*}-\sum_{s \in N D} u_{s}^{*} y_{s o}\right)} \\
\sum_{s \in D} u_{s}^{*}\left(y_{s o}+d_{s o}^{y}\right)+\sum_{s \in N D} u_{s}^{*} y_{s o}=\theta^{*}+\frac{\left(1-\theta^{*}\right)\left(\theta^{*}-\sum_{s \in N D} u_{s}^{*} y_{s o}\right)}{\left(1-\sum_{m \in N D} v_{m}^{*} x_{m o}\right)+\left(\theta^{*}-\sum_{s \in N D} u_{s}^{*} y_{s o}\right)} \\
x_{m o}-d_{m o}^{x}>0 \\
d_{m o}^{x} \geq 0 \\
d_{s o}^{y} \geq 0
\end{gathered}
$$

where the symbol $s \in D$ again refers to the set of 'discretionary' outputs; and the symbol $s \in N D$ refers to the set of 'non-discretionary' outputs.

The meaning of function $E$ (32) and $E$ in (33) is to consider only the gaps in discretionary inputs and outputs. The constraint functions (34) and (35) are incorporated in the non-discretionary factors for the efficiency gap. The target values for input reduction and output augmentation with a balanced share - as discussed above - depend on all total input-output scores and the relevant fixed factor cases as presented in Figure 6. The calculated result of (34) will then coincide with the calculated result of (35).

\section{FIGURE 6. ABOUT HERE}

Finally, the optimal solution for an inefficient $\mathrm{DMU}_{0}$ can now be expressed by means of (39)-(42).

$$
\begin{aligned}
& x_{m o}^{* *}=x_{m o}-d_{m o}^{\chi_{o}^{*}}-s^{-* *}, m \in D \\
& y_{s o}^{* *}=y_{s o}+d_{s o}^{y^{*}}+s^{+* *}, s \in D \\
& x_{m o}^{* *}=x_{m o}, \quad m \in N D \\
& y_{s o}^{* *}=y_{s o}, \quad s \in N D
\end{aligned}
$$

The slacks $s^{-* *}, m \in N D$ and $s^{+* *}, s \in N D$ are not incorporated in (41) and (42), because these factors are evidently 'fixed 'or 'non-discretionary' inputs and outputs, in a way similar to the Banker and Morey (1986) model outlined above. This approach will hereafter be described as the EDM-FF approach. So, we have a series of adjusted DEA models and their differences will be compared in our empirical application to Italian tourist areas. 


\section{Empirical analysis of tourism efficiency of Italian regions}

\subsection{Analysis framework}

In the introductory section we stressed the need for competitive tourism policies amongst tourist destinations. Tourist areas need - under competitive conditions - to obtain proper insight into their relative advantages and disadvantages, as measured by their relative output performance in relation to the use of their scarce resources. This means that DEA may be a strategic decision tool. We now use the DEA and EDM approach described above to undertake a comparative study on possible efficiency improvements of Italian tourist regions. We have carried out an efficiency evaluation and efficiency improvement analysis, as shown in Figure 7.

In Section 6.2, we will first present the efficiency evaluation results based on the CCR-input (CCR-I) model, and interpret the geographical characteristics of the results. Then, in Section 6.3, we present the efficiency improvement projection results based on the CCR-I and EDM approach, including the EDM-FF models, and compare these with the CCR-I and EDM projections.

\section{FIGURE 7. ABOUT HERE}

\subsection{Efficiency evaluation based on CCR-I}

In our empirical work, we have used the data set built by Cracolici et al. (2008). In their study an extensive data base was used on all 103 Italian regions. Several of these regions have a flourishing economy thanks to their tourist attractiveness, but others - despite a wealth of socio-cultural amenities for tourists - are lagging behind. Therefore, it is important to identify the backgrounds of differences in relative tourism performance among these regions. For this purpose, these authors applied a DEA model for these Italian provinces for the year 2001. The scale of these regions is sufficiently large to encapsulate the main tourist attractions in a given area, so that the spill-overs to other areas are rather modest. In their empirical analysis, the authors considered historico-cultural capital, human capital and labour as relevant input dimensions in equation (3). In their measurement the following proxies were used: regional state-owned cultural patrimony and heritage (CPH) (number of museums, monuments and archaeological sites) standardized for population, tourist school graduates divided by working age population (TSG), and labour units employed in the tourism sector divided by the total regional labour force (ULA) in a given region (for details on this data set, we refer to Cracolici 2005). On the output side two types of performance variables were deployed, viz: domestic bed-nights (DBN) and international bed-nights (IBN) relative to the population of a given region (or tourist destination) ${ }^{1}$. Clearly, these data are proxies, but seem to be reasonable proxies to encapsulate the rather extensive variation in the indicators that mirror the tourist performance in Italian regions. More detailed data (by sector, by region or by type of tourist amenity) are not available for the country as a whole.

Furthermore, we have also included the length of the beaches per $\mathrm{km}^{2}$ (LOB) as an additional input. Given its climate conditions, this is an important attractor of tourism in Italy. The lengths were measured after applying an overlay of provincial

\footnotetext{
${ }^{1}$ Data on output have been obtained from ISTAT (National Statistics Institute) (2001a), while the data on inputs have been obtained from different sources: provincial state-owned cultural patrimony and heritage (number of museums, monuments and archaeological areas) from the Ministry of Cultural Heritage (2001); tourist school graduates from the Ministry of Education; and labour units (ULA) employed in the tourism sector from ISTAT (2001b). Because the statistics from the Ministry of Cultural Heritage do not supply the data of regions and provinces with special statute status (Sicily, Aosta, Trento and Bolzano), for these data we have used as a proxy for cultural heritage the region and province-owned cultural heritage (museums, monuments and archaeological areas) (2001) supplied by the Regional and Provincial Bureaus of Cultural Heritage. Finally, ULA includes the following economic sectors: commerce, repairs, hotels, restaurants, transport and communication.
} 
boundaries on the Google Earth system for Italy. Also beaches of Italy's large lakes have been taken into account; they are found among others in the popular tourism regions in Northern Italy.

As we indicated in the preceding section, some inputs or outputs may have a fixed character, implying that they cannot be changed in immediate effective strategies to improve efficiency. This is an element that has to be taken into account in our efficiency analysis. In the present context, the length of the beaches factor may be interpreted as such a fixed factor. Certainly, in the short run, this factor cannot be changed.

A complete overview of the efficiency evaluation results for the 103 Italian tourist regions based on the CCR model using the EDM approach is given in Figure 8, which demonstrates indeed a striking variation. We notice that efficient DMU's (score=1.000) are in particular: Verbano-Cusio-Ossola, Novara, Bolzano-Bozen, Trento, Verona, Vicenza, Belluno, Venezia, Pordenone, Gorizia, Savona, Rimini, Siena, Teramo, Isernia. Most of these regions are indeed flourishing tourist areas.

\section{FIGURE 8. ABOUT HERE}

To take account of the geographical characteristics impacting on the free choice of DMUs, the DMUs are categorized by means of efficiency scores according to five distinct levels: (1.000), (0.999 to 0.750), (0.749 to 0.500), (0.499 to 0.250), and (0.249 to 0.000). These results are shown in Figures 9 -13. It should be noted that these results are only based on an intra-regional efficiency analysis, so that some statistical variations might also partly be due to edge effects, national tourist policy constraints or historical attitudinal effects (such as destination life cycles in tourist behaviour). It may be recognized that the choice of variables is mainly instigated by empirical availability, while in some cases additional variables might seem plausible (such as the quality of beaches in coastal areas). However, we will present the results here for this limited set of variables.

\section{FIGURES 9-13. ABOUT HERE}

From Figure 9, it is clear that the majority of the eminently efficient provinces (score $=1.000$ ) is found in the northern part of Italy. And, from Figures 10 and 11, it turns out that highly and reasonably performing provinces (with scores 0.999 to 0.500 ) are most often found in the northern and central part of Italy. Next, from Figure 12, it appears that moderately efficient provinces (with scores 0.499 to 0.250 ) are observed more in the central part of Italy. Finally, from Figure 13, we observe that low-efficiency provinces (with scores 0.249 to 0.000 ) are relatively concentrated in the northern and southern part of Italy. It is striking that the perpetual North-South dichotomy in Italian regions is also reflected in the overall problem of relative tourism performance.

\subsection{A comparison of the efficiency improvement projection of the CCR-I, EDM and EDM-FF models}

We have already noticed that the EDM model has four projection types depending on the existence of slacks: non-slack type; input-slack type; output-slack type; and input-output-slack type. We will interpret now the results for a typical region for each of these four categories. The efficiency improvement projection results based on the CCR-I, EDM and EDM-FF approach for representative regions in Italy depend on slack patterns presented in Figures 14 -17 and Table 1. It should be noted here that LOB (length of the beaches) is again interpreted in this application as a fixed factor in a EDM-FF model.

In Table 1 we provide the empirical outcomes for 4 typical Italian tourist regions. We will start with Lucca as an example of a non-slack projection type. This type of projection is illustrated in Figure 14. Other regions in this category of the non-slack projection type can be found in Appendix A. In Table 1 for Lucca, it appears that the EDM projection involves both input reduction and output augmentation, and, clearly, the EDM projection does not involve a uniform ratio. Note that the change ratios in the EDM model are smaller than those in the CCR model, as is also suggested in Figure 14. This illustrates 
that the direction of the steps to be taken to improve the efficiency of the tourist sector in this region is less extreme than in the CCR case.

\section{TABLE 1. ABOUT HERE}

\section{FIGURE 14. ABOUT HERE}

Next, in Table 1 we give the outcomes for Ferrara as an illustration of the input-slack projection type. This type of projection is illustrated in Figure 15. Other regions in this category of the input-slack projection type can again be found in Table A1 (Appendix).

\section{FIGURE 15. ABOUT HERE}

Padova is next presented in Table 1 as an an example of the output-slack projection type. The mapping of this specific projection is next illustrated in Figure 16. In addition, we have included the other regions in this category of the output-slack projection type in Table A1.

\section{FIGURE 16. ABOUT HERE}

Finally, Firenze is presented in Table 1 as an example of the input/output slack projection type. The specific characteristics of this projection is illustrated in Figure 17. Clearly, there are several other regions that fall in this specific category of the input/output slack projection type and these can be found in Table A1 in Appendix A.

\section{FIGURE 17. ABOUT HERE}

\section{$7 \quad$ Conclusion}

In this study we have developed a flexible alternative to a conventional DEA by introducing an EDM model as an alternative option to the CCR model. The difference concerns the direction of the efficiency improvement, which is in our approach based on the actual input and output data features. In addition, in this paper we have extended the idea of distance minimization towards the case of fixed factors, an important issue in many domains of efficiency analysis, since inputs and outputs tend to have varying degrees of flexibility. We have applied these methods as tools for a comparative study of the efficiency of 103 Italian tourist regions.

The results of our DEA experiments are noteworthy. First, they show some similarity to previous investigations undertaken by Cracolici et al. (2008). All these findings suggest that the performance of many Italian tourist regions can be improved considerably. There may, of course, be various reasons for such inefficiencies, such as overinvestment in the (highly cyclical) tourist sector, insufficient marketing of the tourist products in a given area, significant differences in tourist attractiveness factors due to variation in physical geography (e.g., coastal areas) or in historically-determined cultural facilities. Consequently, tourist areas are largely subject to the phenomenon of monopolistic competition and have to find their own competitive destination niche in the market (see also Crouch and Ritchie, 1999).

Our findings turn out to be promising. Our comparative analysis has shown that the standard way of projecting inefficient DMUs on the efficient frontier is just one of the many ways to do this, and that the EDM method in most cases leads to less extreme adjustments in inputs and/or outputs in order for an inefficient DMU to reach a better alternative on the efficient frontier. A great challenge for future research will be to link the findings from our modeling experiments to operational strategies and policy measures of individual regions to bridge their efficiency gap. 
There is still a large research agenda ahead of us. Future research may address in particular: the integration of the EDM model with other types of DEA models (for example, the BCC model or the Ranking DEA model); the simultaneous and integrated treatment of input and output orientation in EDM models with fixed factors; the introduction of different degrees of rigidity in the fixed factor approach; the inclusion of transaction costs in efficiency-improving strategies; and the incorporation of public policy handles (e.g., pricing measures) which also impact on the demand side of tourism. The present study provides no doubt a basis for further future research. Finally, it ought to be recognized that this approach - like any other DEA approach

- has its limitations. Efficiency differences among regions are summarized in a restricted set of indicators; there might be alternative variables that may offer a complementary explanation for interregional efficiency variations. Nevertheless, the power of this approach is that it offers a clear-cut comparative study of the tourist performance of regions, so that regions are in a position to identity the critical success factors for tourist policy from a benchmark perspective.

Acknowledgment: The authors wish to recognize the great support of Francesca Cracolici in creating the data base and giving constructive comments.

\section{References}

Apostolopoulos G, Gayle D (eds) (2001) Island Tourism and Sustainable Development. Praeger, Westport, Connecticut Banker RD Morey RC (1986) Efficiency Analysis for Exogenously Fixed Inputs and Outputs. Operations Research, 34 (4): 513-521

Barros CP (2005) Measuring Efficiency in the Hotel Sector. Annals of Tourism Research 32: 456-477

Chambers RG Chung Y, Fare R (1996) Benefit and distance functions. Journal of Economic Theory 70: 407-419

Charnes A, Cooper WW, Rhodes E (1978) Measuring the Efficiency of Decision Making Units. European Journal of Operational Research 2: 429-444

Coccossis H, Mexa A(2004) Tourism Carrying Capacity. Ashgate, Aldershot

Cooper WW, Seiford LM, Tone K (2006) Introduction to Data Envelopment Analysis and its Uses. Springer-Verlag, Berlin

Cracolici MF (2005) La Competitività tra Destinazioni Turistiche. Un'Analisi di Destination Benchmarking. PhD Dissertation Faculty of Economics, University of Palermo, Italy

Cracolici MF, Nijkamp P, Rietveld P (2008) Assessment of Tourism Competitiveness by Analysing Destination Efficiency. Tourism Economics 14(2): 325-342

Crouch GI, Ritchie JRB (1999) Tourism, Competitiveness and Societal Prosperity. Journal of Business Research 44:147-152 Fusco Girard L, Nijkamp P (eds) (2009) Cultural Tourism and Sustainable Local Development. Ashgate, Aldershot, UK

Giaoutzi M, Nijkamp P (eds) (1993) Decision Support Models for Regional Sustainable Development. Ashgate, Aldershot, UK

Giaoutzi M, Nijkamp P (eds) (2006) Tourism and Regional Development: New Pathways. Ashgate, Aldershot, UK

Goicoechea A, Duckstein L, Zionts S (eds) (1992) Multiple Criteria Decision Making. Springer-Verlag, Berlin

Heath E, and Wall G (1992) Marketing Tourism Destinations. John Wiley, New York

ISTAT (2001a) Statistiche del Turismo. ISTAT, Roma

ISTAT (2001b) Dati di Contabilità Nazionale. ISTAT, Roma

Matias A, Neto P, Nijkamp P (eds) (2007) Advances of Modern Tourism Research.. Springer-Verlag, Berlin

Morey RC, Dittman D.A. (1995) Evaluating a hotel GM's performance. A case study in benchmarking. Cornell Hotel and Restaurant Administration Quarterly 36(5): 30-35

Nelson FG Butler R, Wall G (eds) (1993) Tourism and Sustainable Development. University of Waterloo, Dept of Geography, Waterloo

Nijkamp P, Rietveld P, Voogd H (1990) Multicriteria Evaluation in Physical Planning. Elsevier, Amsterdam 
Ryan C, Aicken M (eds) (2005) Indigenous Tourism. Elsevier, Amsterdam

Sawaragi Y, Nakayama H, Tanino T (1985) Theory of multiobjective optimization. Academic Press, Orlando, Florida Shaw G, Williams A (2002) Critical Issues in Tourism. Blackwell, Oxford

Steuer RE (1986) Multiple Criteria Optimization. John Wiley, New York

Tisdell C (2001) Tourism Economics, The Environment and Development. Edward Elgar, Cheltenham, UK

Wall G Mathieson AS (2006) Tourism, Change, Impacts and Opportunities. Prentice Hall, Harlow 
Table 1. A comparison of efficiency improvement projection results of CCR, EDM and EDM -FF (examples: Lucca, Ferrara, Padova and Firenze)

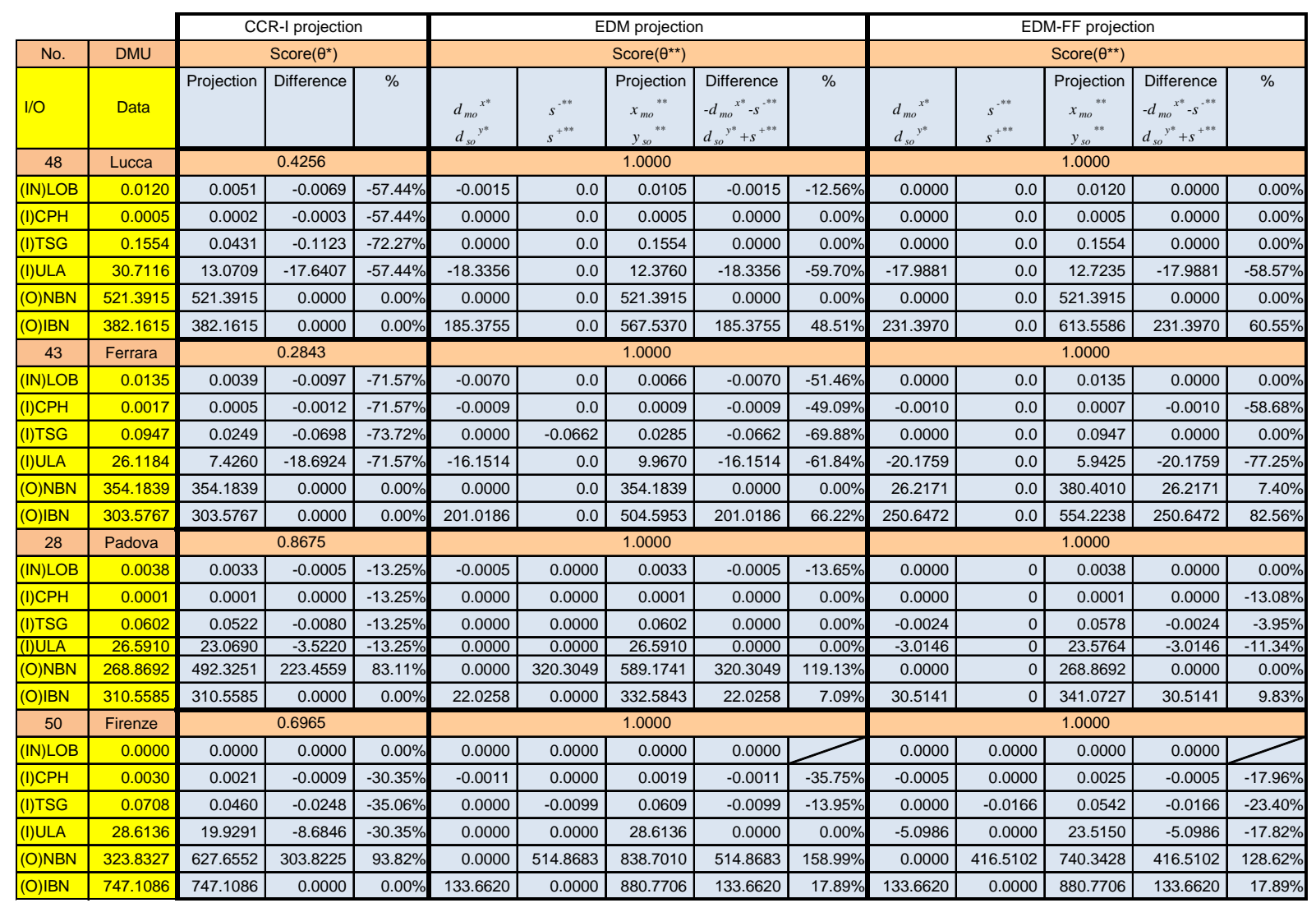

Note: See Section 6.2 for an explanation of abbreviations 


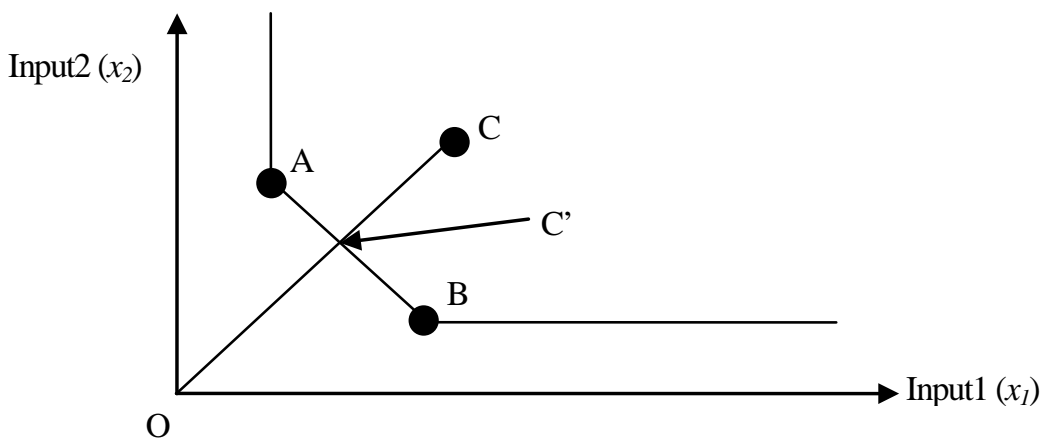

Fig. 1. Illustration of original DEA projection in Input space

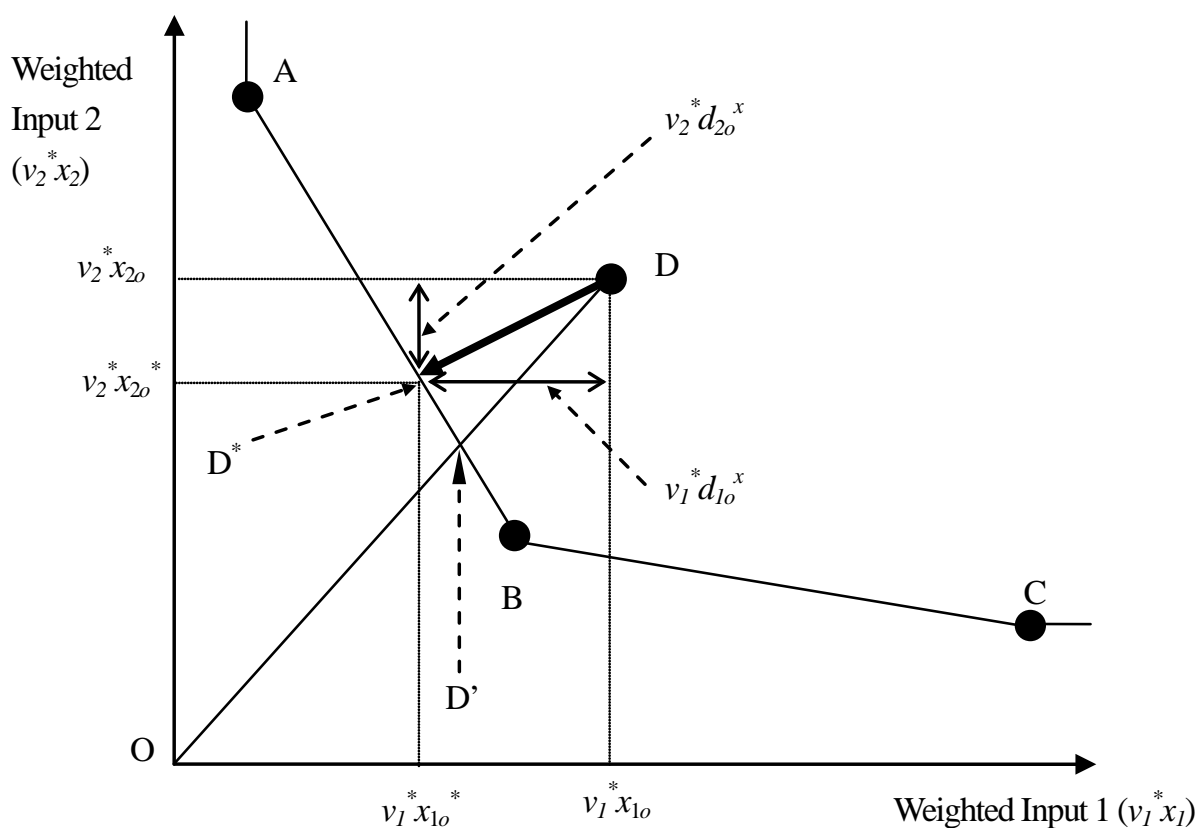

Fig. 2. Illustration of EDM approach (Input- $v_{i}^{*} x_{i}$ space) 


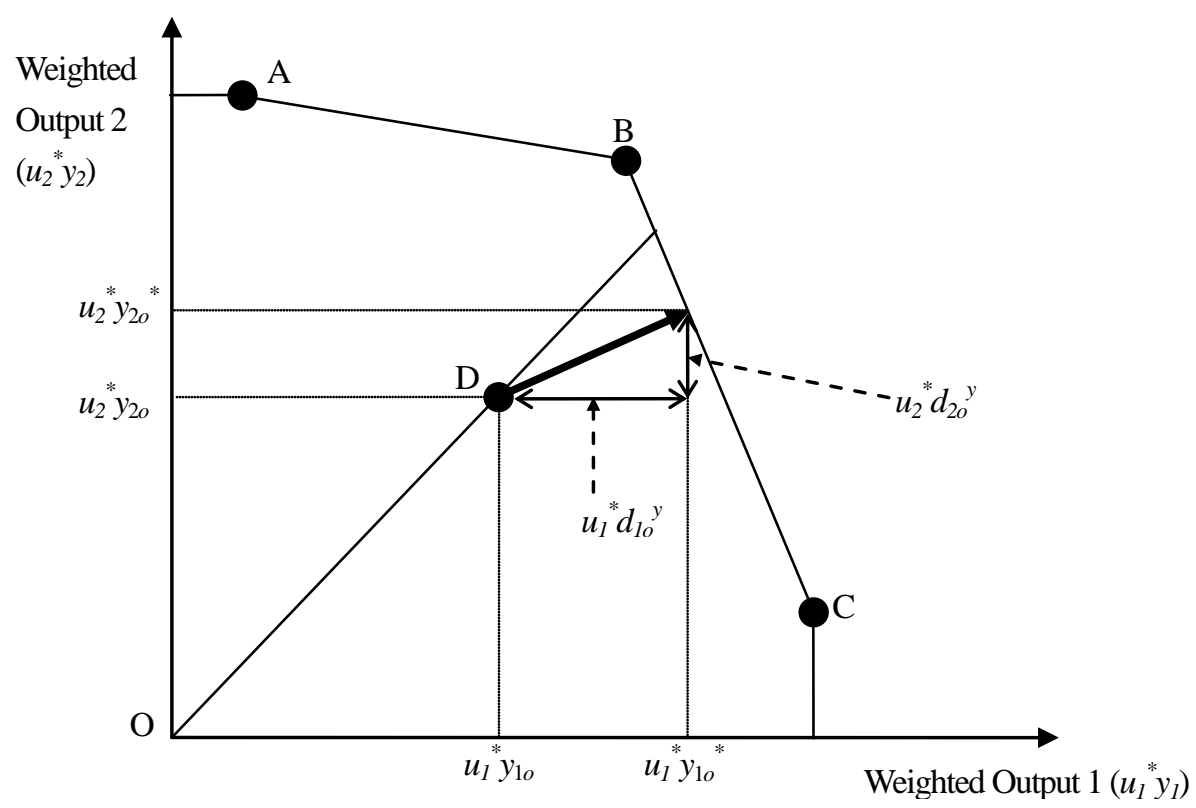

Fig. 3. Illustration of EDM approach (Output - $u_{r}^{*} \mathrm{y}_{r}$ space)

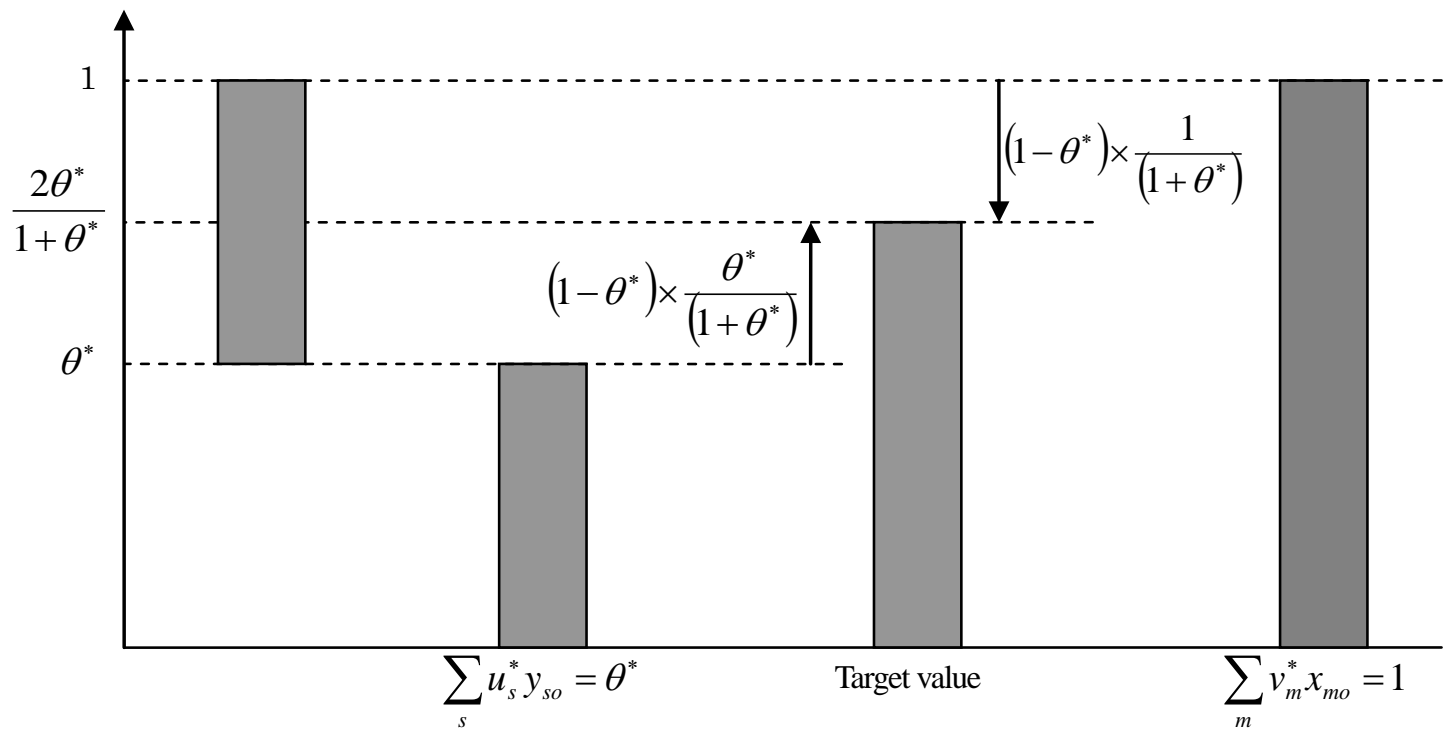

Fig. 4. Presentation of balanced allocation for the total efficiency gap 1- $\theta^{*}$ 


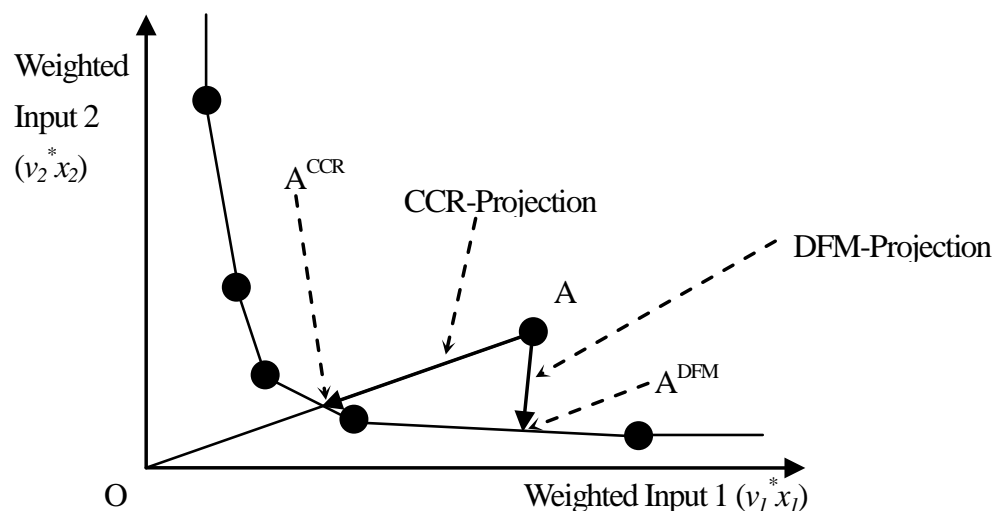

Fig. 5. Degree of improvement of EDM-projection and CCR-projection in weighted-input space

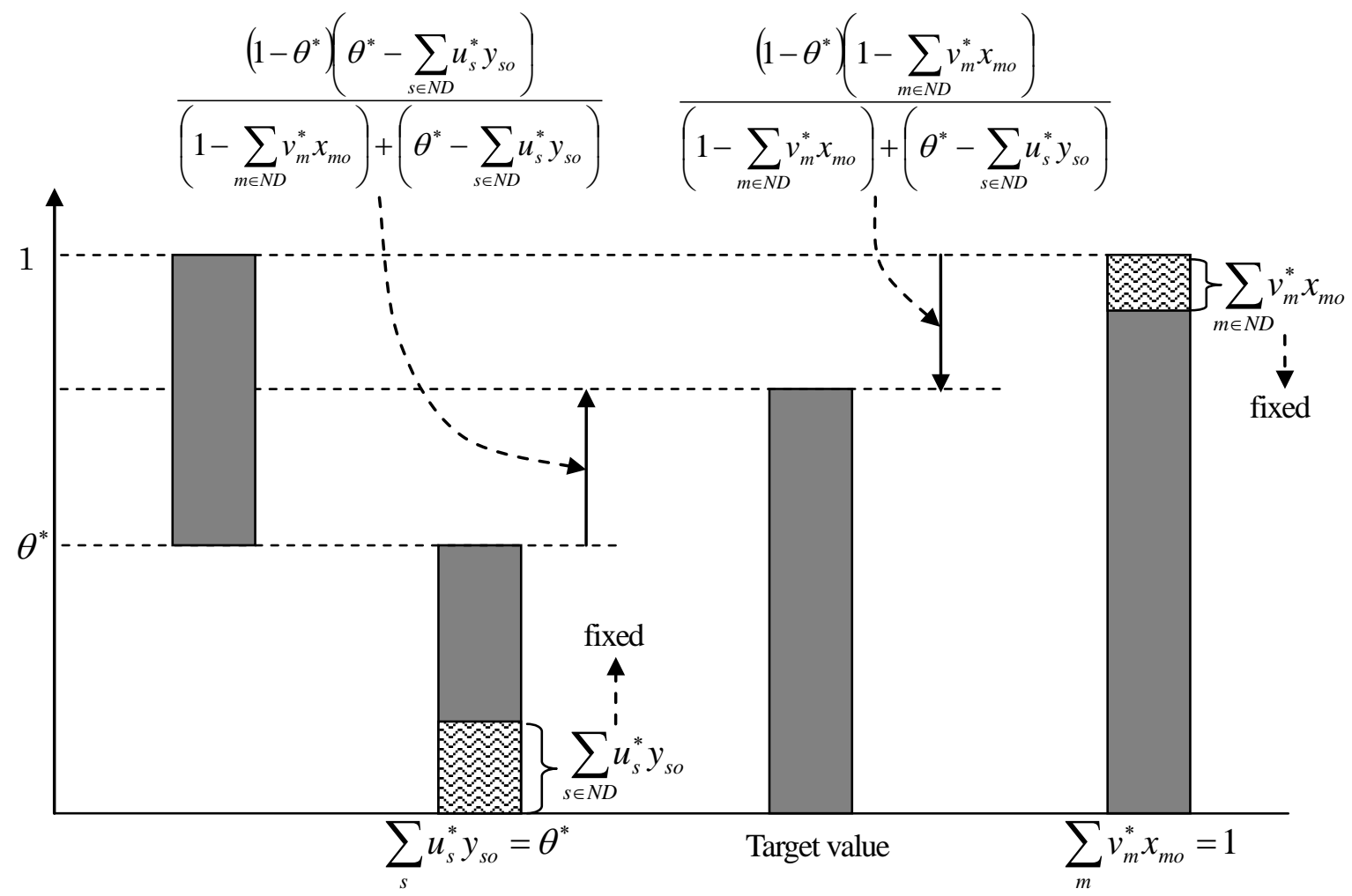

Fig. 6. The distribution of total efficiency gap 1- $\theta^{*}$ 


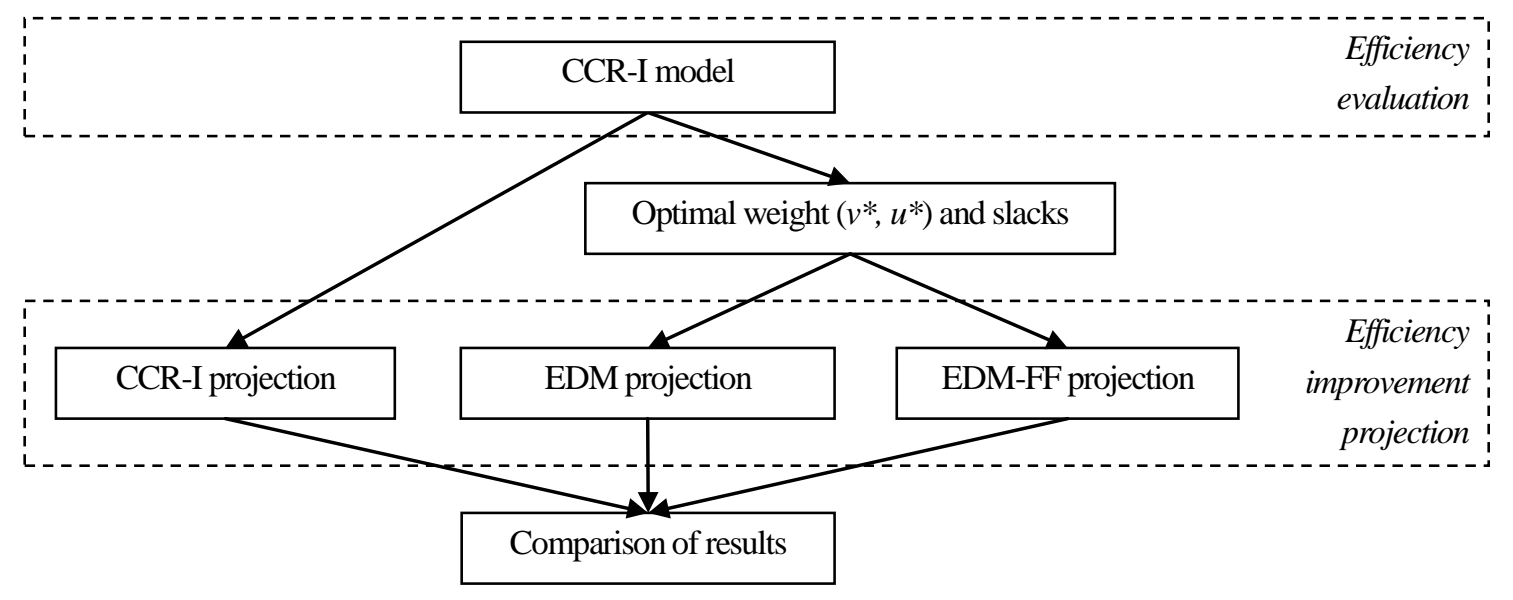

Fig. 7. Analytical framework of CCR-I, EDM and EDM-FF model
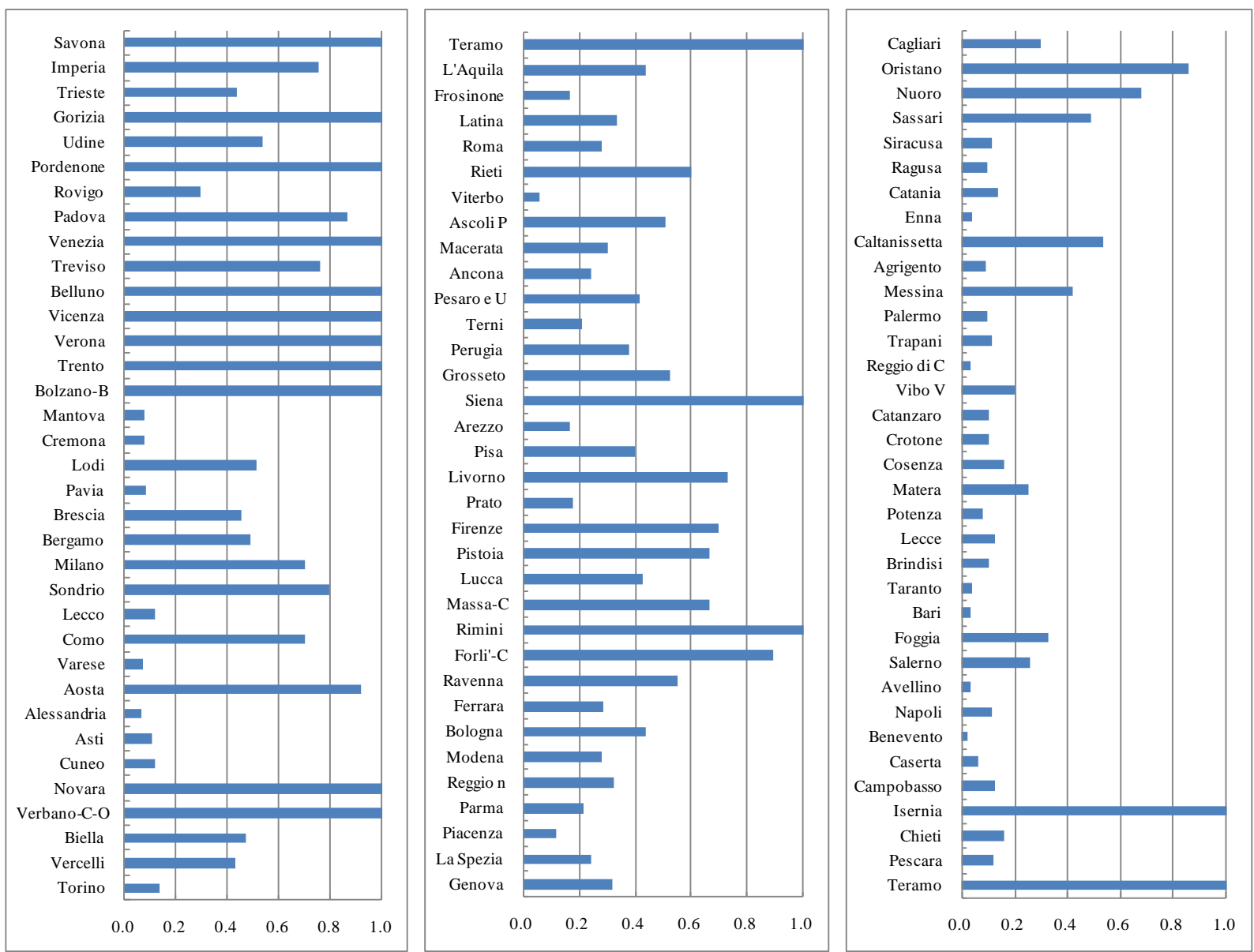

Fig. 8. Efficiency evaluation result of CCR model 


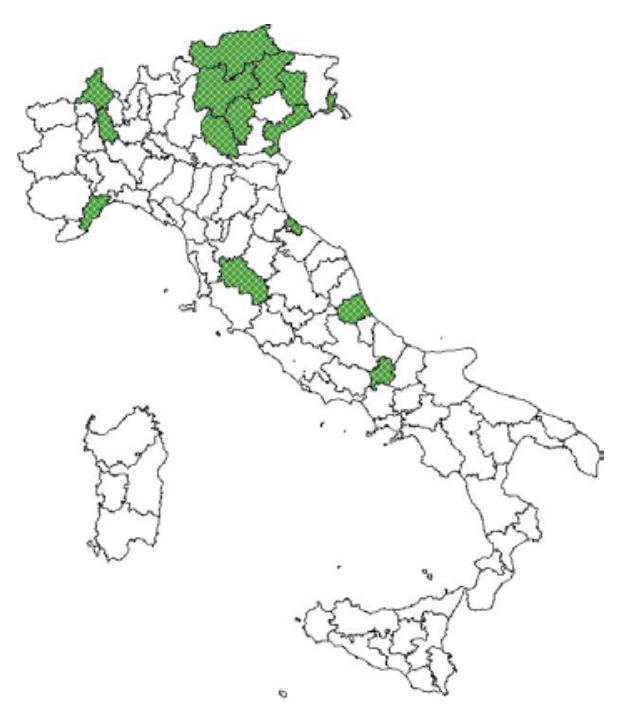

Fig. 9. Provinces with score 1.000

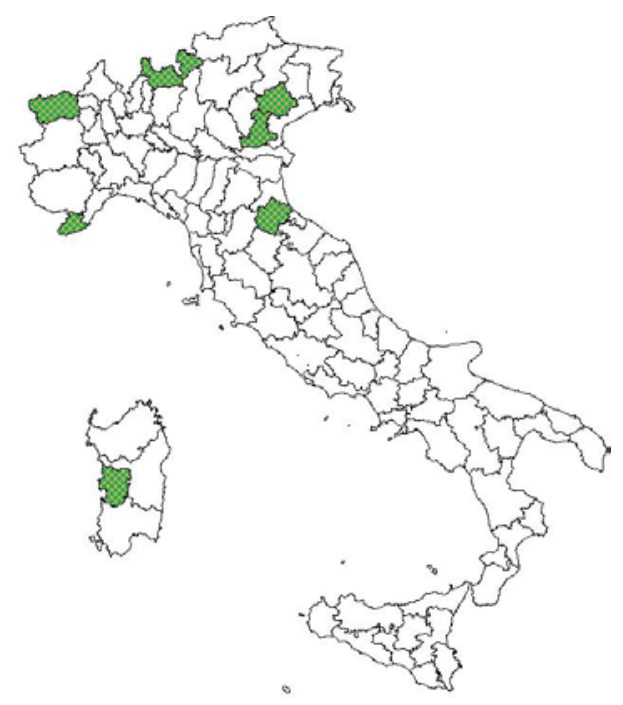

Fig. 10. Provinces with score 0.999 to 0.750
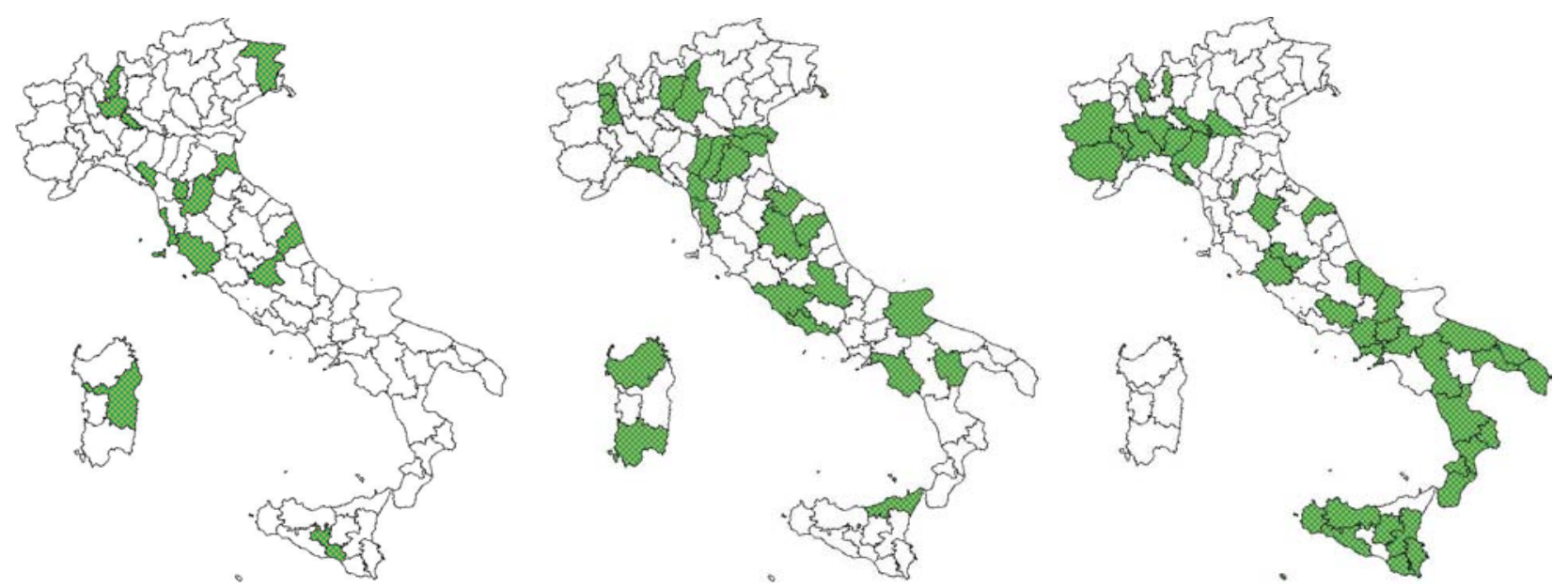

Fig. 11. Provinces with score

0.749 to 0.500
Fig. 12. Provinces with score 0.499 to 0.250
Fig. 13. Provinces with score 0.249 to 0.000 

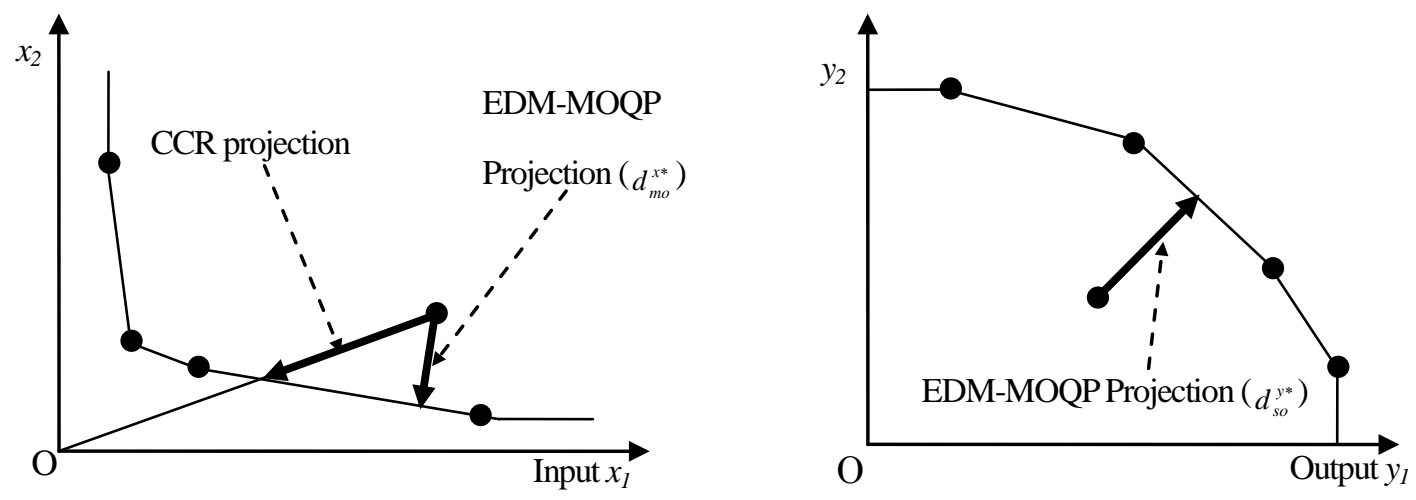

Fig. 14. Illustration of Non-slack projection type
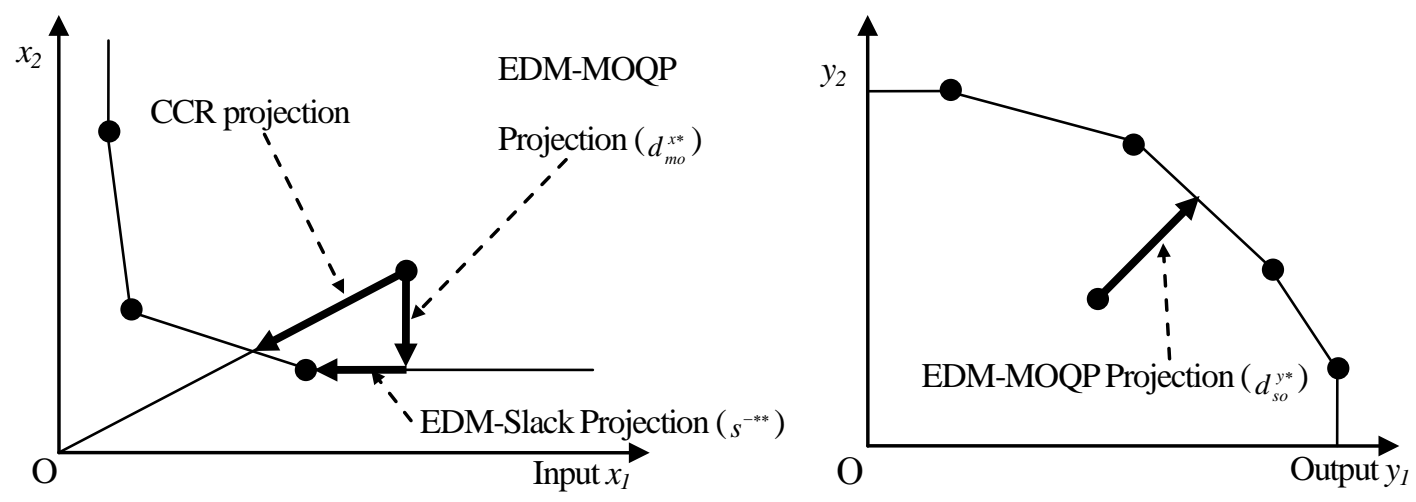

Fig. 15. Illustration of Input-slack projection type
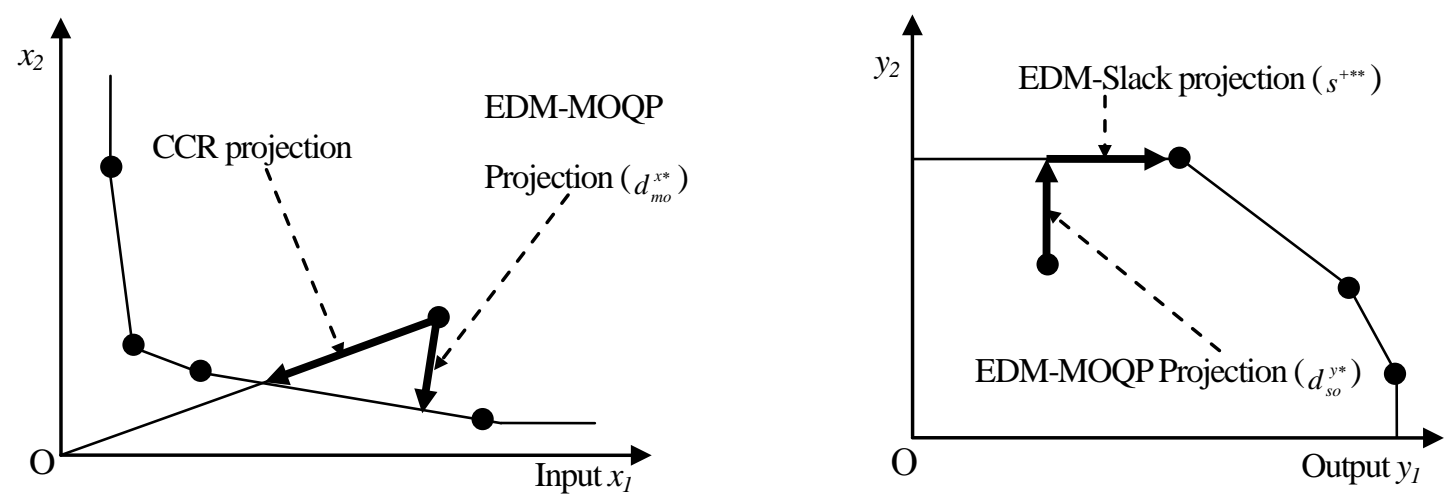

Fig. 16. Illustration of Output-slack projection type 

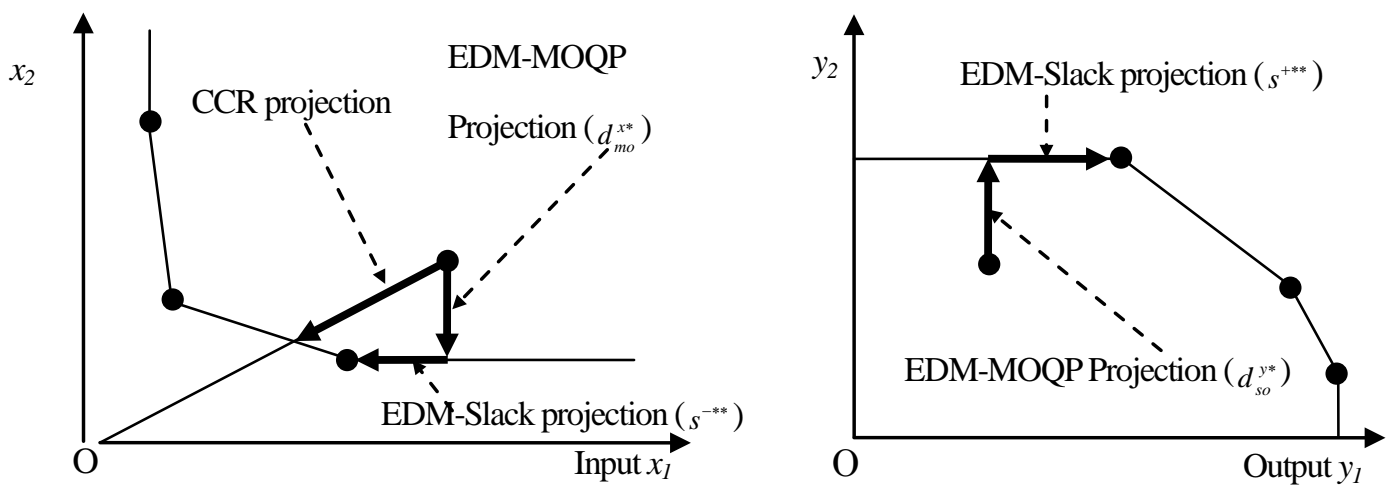

Fig. 17. Illustration of Input/Output-slack projection type 
Table A1. EDM model slack projection type for all DMUs ${ }^{1}$

\begin{tabular}{|c|c|c|c|c|c|c|c|c|}
\hline No. & DMU & $\begin{array}{l}\text { Type of } \\
\text { Slack }\end{array}$ & No. & DMU & $\begin{array}{c}\text { Type of } \\
\text { Slack }\end{array}$ & No. & DMU & $\begin{array}{c}\text { Type of } \\
\text { Slack }\end{array}$ \\
\hline 1 & Torino & OS & 36 & Genova & IS & 70 & Pescara & NS \\
\hline 2 & Vercelli & IOS & 37 & La Spezia & NS & 71 & Chieti & NS \\
\hline 3 & Biella & OS & 38 & Piacenza & NS & 72 & Isernia & EFI \\
\hline 4 & Verbano-Cusio-Ossola & EFI & 39 & Parma & NS & 73 & Campobasso & NS \\
\hline 5 & Novara & EFI & 40 & Reggio nell'Emilia & NS & 74 & Caserta & NS \\
\hline 6 & Cuneo & IOS & 41 & Modena & NS & 75 & Benevento & IOS \\
\hline 7 & Asti & OS & 42 & Bologna & OS & 76 & Napoli & IS \\
\hline 8 & Alessandria & IS & 43 & Ferrara & IS & 77 & Avellino & NS \\
\hline 9 & Aosta & IS & 44 & Ravenna & NS & 78 & Salerno & NS \\
\hline 10 & Varese & NS & 45 & Forli'-Cesena & NS & 79 & Foggia & NS \\
\hline 11 & Como & IOS & 46 & Rimini & EFI & 80 & Bari & NS \\
\hline 12 & Lecco & NS & 47 & Massa-Carrara & NS & 81 & Taranto & IOS \\
\hline 13 & Sondrio & NS & 48 & Lucca & NS & 82 & Brindisi & NS \\
\hline 14 & Milano & OS & 49 & Pistoia & IOS & 83 & Lecce & NS \\
\hline 15 & Bergamo & NS & 50 & Firenze & IOS & 84 & Potenza & IOS \\
\hline 16 & Brescia & NS & 51 & Prato & IOS & 85 & Matera & NS \\
\hline 17 & Pavia & NS & 52 & Livorno & NS & 86 & Cosenza & NS \\
\hline 18 & Lodi & OS & 53 & Pisa & NS & 87 & Crotone & IOS \\
\hline 19 & Cremona & NS & 54 & Arezzo & NS & 88 & Catanzaro & IOS \\
\hline 20 & Mantova & OS & 55 & Siena & EFI & 89 & Vibo Valentia & NS \\
\hline 21 & Bolzano-Bozen & EFI & 56 & Grosseto & NS & 90 & Reggio di Calabria & IOS \\
\hline 22 & Trento & EFI & 57 & Perugia & NS & 91 & Trapani & NS \\
\hline 23 & Verona & EFI & 58 & Terni & NS & 92 & Palermo & NS \\
\hline 24 & Vicenza & EFI & 59 & Pesaro e Urbino & NS & 93 & Messina & IS \\
\hline 25 & Belluno & EFI & 60 & Ancona & NS & 94 & Agrigento & NS \\
\hline 26 & Treviso & IOS & 61 & Macerata & IOS & 95 & Caltanissetta & IOS \\
\hline 27 & Venezia & EFI & 62 & Ascoli Piceno & NS & 96 & Enna & NS \\
\hline 28 & Padova & OS & 63 & Viterbo & NS & 97 & Catania & NS \\
\hline 29 & Rovigo & NS & 64 & Rieti & IOS & 98 & Ragusa & NS \\
\hline 30 & Pordenone & EFI & 65 & Roma & NS & 99 & Siracusa & IS \\
\hline 31 & Udine & NS & 66 & Latina & NS & 100 & Sassari & NS \\
\hline 32 & Gorizia & EFI & 67 & Frosinone & NS & 101 & Nuoro & NS \\
\hline 33 & Trieste & IS & 68 & L'Aquila & NS & 102 & Oristano & IS \\
\hline 34 & Imperia & IS & 69 & Teramo & EFI & 103 & Cagliari & NS \\
\hline
\end{tabular}

Note 1: $\quad$ NS = Non-slack projection type

IS = Input-slack projection type

OS = Output-slack projection type

IOS = Input/Output-slack projection type

$\mathrm{EFI}=$ Efficient DMU 